\title{
Mitigation of estuarine eutrophication processes by controlling freshwater inflows
}

\author{
A. A. L. S. Duarte \& J. M. P. Vieira \\ Department of Civil Engineering, University of Minho, Braga, Portugal
}

\begin{abstract}
Residence time is broadly recognised as a key-parameter to assess estuarine eutrophication vulnerability since it is related to the eutrophication gradients observed in many estuarine systems. The increase of estuarine flushing capacity can be seen as a management measure to mitigate or to invert eutrophication processes. The southern arm of the Portuguese river Mondego estuary was strongly stressed by an eutrophication process due to massive nutrient loading from urbanised areas, aquaculture farms and agricultural land runoff. A research work was carried out in the development of a hydroinformatic tool (MONDEST model) for the description and assessment of freshwater inflows effects on residence time spatial variation in estuarine systems. This tool was applied in the identification of the most critical zones subjected to an eutrophication process, considering different hydrodynamic scenarios. MONDEST model can be a powerful tool for enhancing wetland eutrophication vulnerability assessment in order to establish the best water quality management practices and restoration measures for the environmental sustainability of this complex aquatic ecosystem. Keywords: estuarine sustainable management, wetlands, hydroinformatics, eutrophication, residence time, Mondego estuary.
\end{abstract}

\section{Introduction}

Coastal zones and estuarine habitats are among the most productive ecosystems on Earth, and in many locations they are subjected to a variety of anthropogenic stressors, such as pollution and eutrophication. The importance of estuarine ecosystems is recognised worldwide, for providing essential ecological functions (fish nursery, decomposition, nutrient cycling and flux regulation of water, particles and pollutants) and services shoreline protection, fisheries resources, 
harbours, and recreational purposes As transitional areas between land and sea, most estuaries and coastal lagoons receive large amounts of nutrients and pollutants inputs derived from urban, agricultural and industrial effluents [1], leading to sensitive structural changes in estuarine ecosystems due to strong stimulation of opportunistic macroalgae growth, with the consequent occurrence of algal blooms. As a response to this, there has been an enormous increase in restoration plans for reversing habitat degradation, based on knowledge of the processes which driven the observed ecological changes [2,3].

The hydrology and the ecology of shallow estuarine areas are strongly influenced by the freshwater inflow and the adjacent open sea, creating salinity gradients, thermal stratification and assuring large transport of silt, organic material and inorganic nutrients to the estuaries. So, the influence of the hydrodynamics must not be neglected on estuarine eutrophication vulnerability assessment, because flushing time is determinant for the transport capacity and the permanence of substances inside an estuary $[4,5]$.

Residence time (RT) values can be of paramount interest to assess estuarine eutrophication vulnerability, considering the effects of tides, wind and river discharges on salinity gradients and nutrients dilution. RT is a convenient parameter representing the time scale of physical transport processes, and often used for comparison with time scales of estuarine biochemical processes $[6,7]$. But, the concept of a single residence time per estuary, while convenient from both ecological and engineering viewpoints, is therefore shown to be an oversimplification [8]. A pollutant will exert most of its effects within an estuary if its biochemical time scales are comparable to, or shorter than the residence time [9]. In fact, estuaries with nutrients residence time values, shorter than the algal cells doubling time, will inhibit algae blooms occurrence. The increase of estuarine flushing capacity can be seen as a crucial management measure to mitigate or to invert eutrophication processes [10].

For some decades, the river Mondego estuary (fig. 1) has been under severe ecological stress, mainly caused by eutrophication of its south arm due to the combination of the nutrient surplus with low hydrodynamics and high salinity.

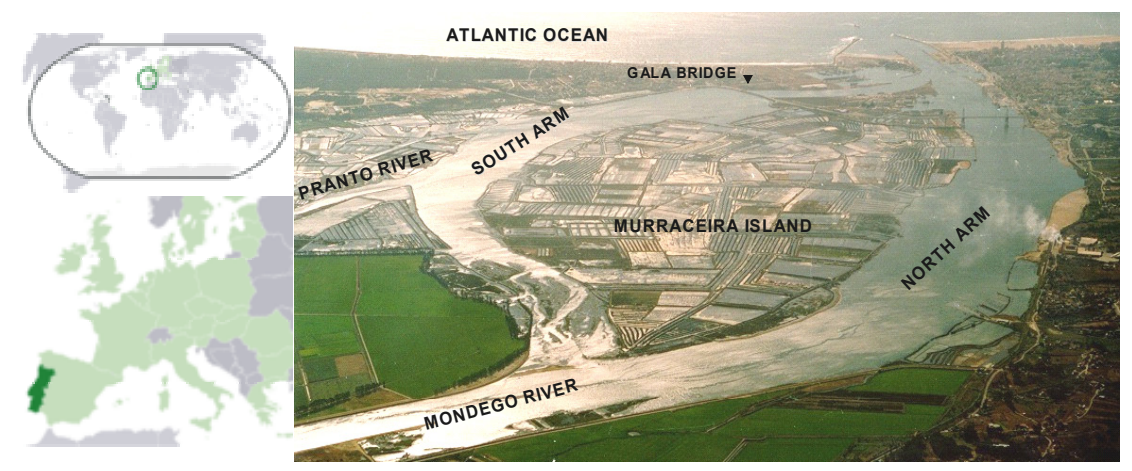

Figure 1: Location and aerial view of river Mondego estuary. 
Until the end of 1998 this sub-system was almost silted up in the upstream areas, drastically reducing the Mondego river water inflow. So, water circulation was therefore mainly dependent on tides and on the freshwater input from the Pranto River, artificially controlled by a sluice, according to rice field irrigation needs in the lower Mondego valley [11]. The most visible effect of this important hydrodynamic constrain was the occurrence of episodic macroalgae blooms and the concomitant decrease of the area occupied by Zostera noltii beds (fig 2) [12].
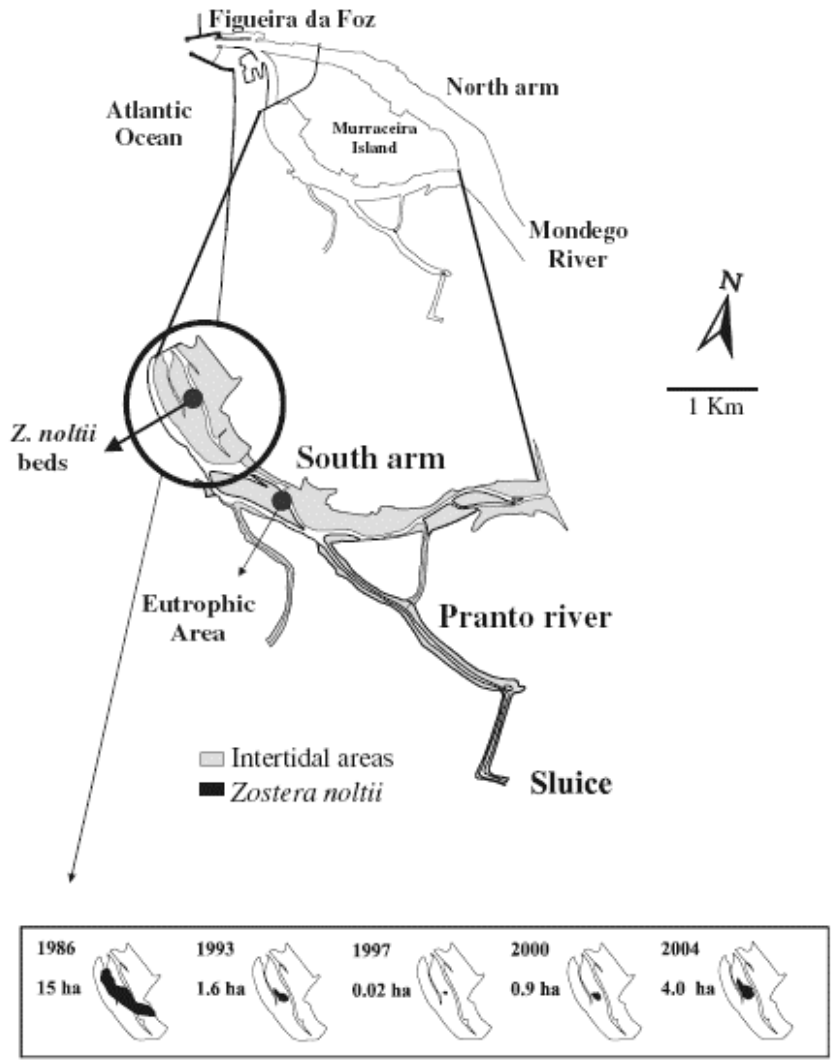

Figure 2: Location of Zostera noltii beds and change of its coverage area in the south arm of the Mondego estuary.

Thus, the development of a hydroinformatic tool for estuarine transport processes characterization was obviously pertinent and useful. This paper presents a water quality model for the Mondego estuary (MONDEST model), which was developed and calibrated in order to simulate its hydrodynamics, salinity and residence times spatial distributions, at different simulated management scenarios. 
The results of the model simulations, considering different river water flow scenarios, illustrate the strong asymmetry of flood and ebb duration time at the inner sections of this estuary, a key-parameter for a correct tidal flow estimation, as the major driving force of the southern arm flushing capacity. RT values, estimated using the TempResid module, are shown to have strong spatial and temporal variability. The higher values, obtained in this work, are concerning with the most vulnerable areas as it is observed in this eutrophication process.

The conclusions of this work were a useful contribution to support the design of a sustainable management plan, based on nutrient loads reduction, river Pranto local discharge change and hydrodynamic circulation improvement, and the adopted methodology can be applied to assess the real impact of these mitigation measures on the restoration process of this complex aquatic ecosystem.

\section{Materials and methods}

\subsection{Study site}

The river Mondego estuarine system is about $29 \mathrm{~km}$ long, between river mouth and Formoselha Bridge (upstream tidal river section). The Mondego estuary main zone (fig. 1) only about $10 \mathrm{~km}$ long and $3 \mathrm{~km}$ across at its widest part and comprises a northern and a southern arm, separated by the Murraceira Island.

The bathymetry of both arms shows a strong morphological irregularity (fig. 3): the northern arm is deeper $(10 \mathrm{~m}$, during high tide) constitutes the main navigation channel of the Figueira da Foz mercantile harbour and receives the majority of freshwater input (from Mondego river), while the southern arm is shallower ( 2 to $4 \mathrm{~m}$ ) and was almost silted up in the upstream area.

Consequently, the southern arm estuary water circulation is mainly forcing by tides, wind and the usually small freshwater input of Pranto River, a tributary
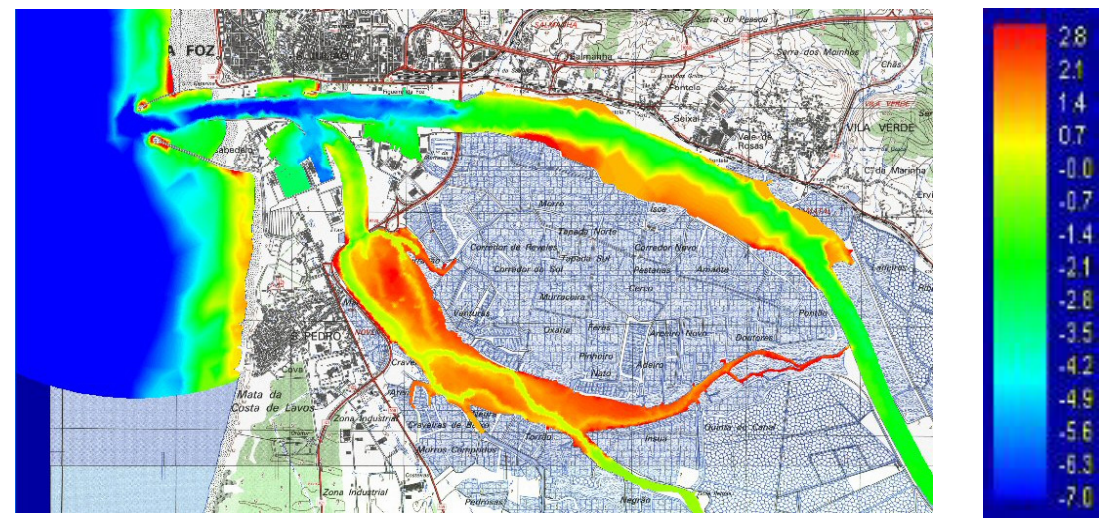

Figure 3: Bathymetry of the Mondego estuary main zone (high tide). 
artificially controlled by sluices, which can discharge to the both arms, regulated according to the water level of rice fields in the Mondego Valley.

The southern arm is also characterised by large areas of intertidal flats exposed during low tide, corresponding to more than $75 \%$ of the total southern arm area $\left(2.3 \mathrm{~km}^{2}\right)$, that are a strong influence on its hydrodynamic behaviour leading to a big asymmetry on flooding and ebbing times at the inner areas [3]. In this arm, eutrophication has triggered serious biological changes, which led to a progressive replacement of seagrass (Zostera noltii) by opportunistic macroalgae. Green macroalgae blooms have been observed in the southern arm, due to: the simultaneous occurrence of the water residence time increase, related with its progressive upstream silting up process [13]; the sunlight and temperature favourable conditions; and the high availability of nitrogen and phosphorus discharged by oriziculture and aquaculture activities. So, it became crucial to obtain better information about the major mechanisms, like hydrodynamics and nutrients annual balance, which can regulate the abundance of opportunistic macroalgae and identify the most vulnerability zones to the eutrophication processes.

\subsection{Sampling program}

A sampling program was carried out during last two decades at three benthic stations and at three other sites (river Pranto mouth, Armazéns channel mouth and Gala bridge) for water column monitoring. The choice of benthic stations location was related with the observation of an eutrophication gradient in the south arm of the estuary. The location of water monitoring stations at Mondego estuary south arm are selected in order to represent the different flow regimes observed in this system. So, water level, velocity, salinity, temperature and dissolved oxygen were measured in situ and water samples were collected for physical and chemical system characterization and also for nutrients annual balance estimation. The fraction more representative on the nutrients transport was the one dissolved on water, followed by the suspended particulate matter fraction. The former is also an important factor on the eutrophication process, since represents the nutrients immediately accessible to the macroalgae tissues incorporation on the growing process.

The available data analysis allowed concluding that dissolved and particulate the occurrence of green macroalgae blooms is strongly dependent on the flushing conditions, salinity gradients and nutrient loading characteristics [14].

\subsection{Hydroinformatic tool}

Numerical modelling is a multifaceted tool to get a better understanding of physical, chemical and biological processes in the water bodies, based on a "simplified version of the real" described by a set of equations, which are usually solved by numerical methods. The models to be used for the implementation of the Water framework Directive (WFD) should ideally have the highest possible degree of integration to comply with the integrated river basin approach, 
coupling hydrological, hydrodynamic, water quality and ecological modules as a function of the specific environmental issues to analyse [15].

The Mondego Estuary (MONDEST) model was conceptualized integrating hydrodynamics, water quality and residence time calculation (TempResid) modules (fig. 4), and based on generic package models [16, 17] which were adapted to this specific estuarine ecosystem. A hydroinformatic tool was development for this estuarine system coupling hydrodynamics, water quality and residence time (RT) calculation (TempResid) modules (fig 4).

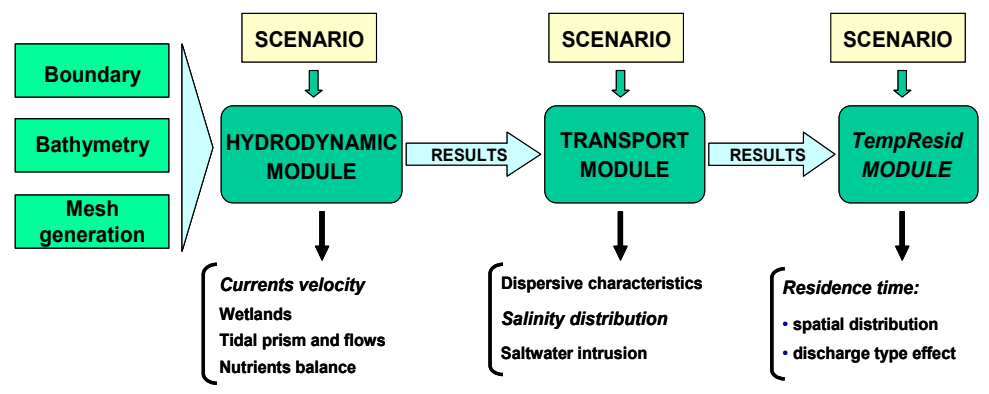

Figure 4: The MONDEST model conceptualization.

In this hydroinformatic tool, the mesh generation was optimised by an iterative refinement process in order to perform a better adjustment to the geometric and bathymetric irregularities of all estuarine system and to solve some numerical "instabilities" during the automatic calculation process. Figure 5 presents the finite element mesh $(2 \mathrm{D}-\mathrm{H})$ which was considered in the hydrodynamic modelling.

For analyse and comparison of the simulation results several control points were defined in both Mondego estuary arms: north (N1-N6) and south (S1-S5), as depicted in Figure 6.

The hydrodynamic module provides flow velocities and water levels for the water transport module, which acts as input to the TempResid module, feeding constituents' concentration over the modelled system and allowing estuarine dispersive behaviour characterization.

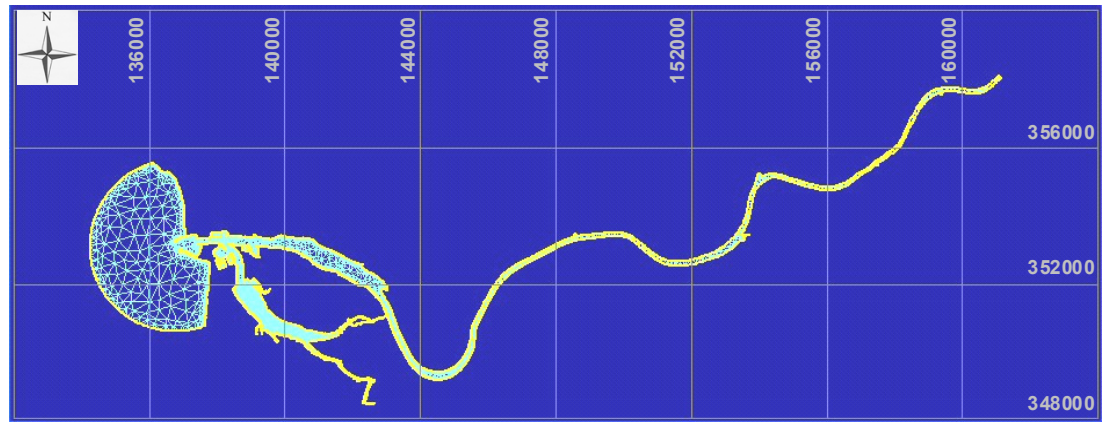

Figure 5: The finite element mesh (2D-H) used in the hydrodynamic modelling. 


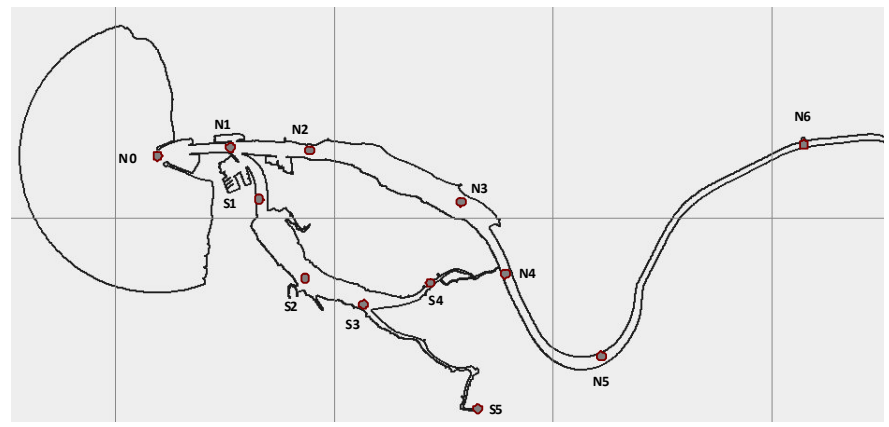

Figure 6: Location of the control points selected for the results analysis.

The velocities and water levels field data, obtained from the referred sampling program, were used to calibrate, validate and define the boundary conditions of MONDEST hydrodynamic module. Figure 7 shows an example of calibration procedure related with surface water level at Gala station (S1), considering different tidal regime (spring and neap tides)

The transport module calibration and validation was performed at different sampling stations, with the salinity values provided by field data, in order to estimate the horizontal dispersion coefficients (fig. 8).

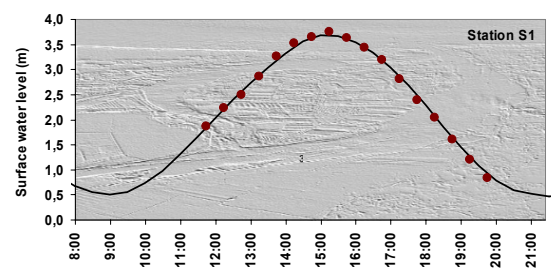

Time (h)

—MONDEST results $\bullet$ measured value (spring tide)

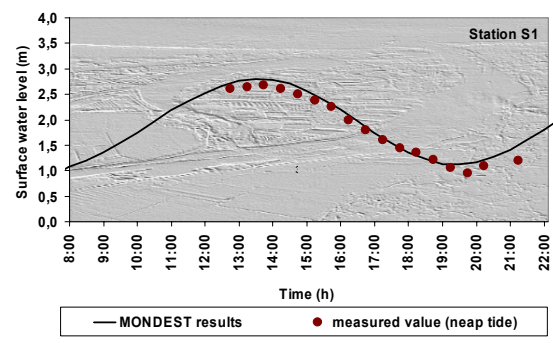

Figure 7: Hydrodynamic module calibration (surface water level at Gala station).

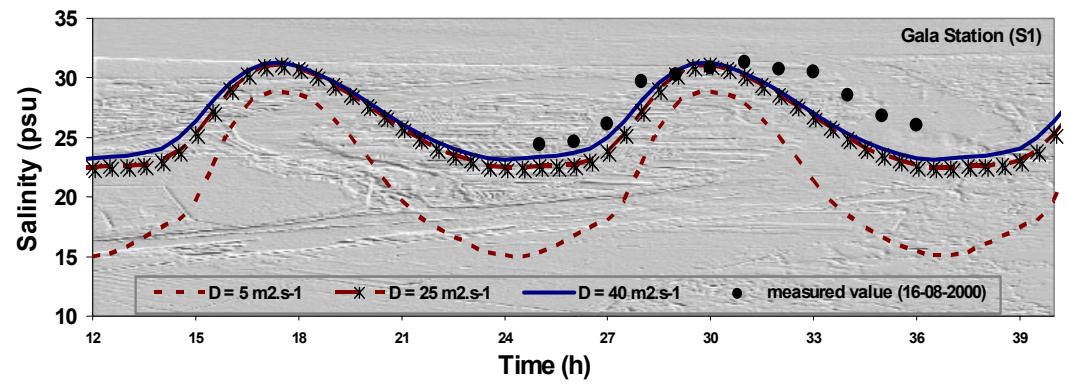

Figure 8: $\quad$ Transport module calibration at Gala station (S1). 
TempResid module was integrally developed in this work as a new approach for RT values calculation for each constituent over all the system and allows mapping RT spatial distribution at different simulated hydrodynamic scenarios. The recommended method for MONDEST model application, with success, to estuarine water quality management is based on a wide, but judicious, range of simulation scenarios, considering representative tidal and freshwater inflow regimes, as well as pollutant decay rates and discharging characteristics (location, point or diffuse, time release, ebbing or flooding period of the tidal cycle). Table 1 presents some simulated scenarios adopted for hydrodynamic influence assessment on estuarine eutrophication processes based on RT computing and spatial distribution.

Figure 9 shows an example of MONDEST model transport module results for management scenario RT1. This graph presents the concentration decrease of a conservative constituent, in three control points ( $\mathrm{N} 0, \mathrm{~S} 1$ and S3) due to estuarine flushing currents, considering the re-entrance phenomena at the estuary mouth.

Table 1: Simulation scenarios for Mondego estuary eutrophication assessment.

\begin{tabular}{|c|c|c|c|c|c|}
\hline \multirow[t]{2}{*}{ SCENARIO } & \multicolumn{2}{|c|}{$\begin{array}{c}\text { RIVER FLOW } \\
\left(\mathrm{m}^{3} \cdot \mathrm{s}^{-1}\right)\end{array}$} & \multirow[t]{2}{*}{ TIDE } & \multirow[t]{2}{*}{ LOAD } & \multirow{2}{*}{$\begin{array}{l}\text { DECAY RATE } \\
\text { (day }^{-1} \text { ) }\end{array}$} \\
\hline & \begin{tabular}{|l|} 
Mondego \\
\end{tabular} & Pranto & & & \\
\hline RT 1 & \multirow{6}{*}{15} & \multirow{5}{*}{0} & medium & \multirow{9}{*}{ point } & \multirow{3}{*}{0} \\
\hline RT 2 & & & \multirow{2}{*}{\begin{tabular}{|c|} 
spring \\
neap \\
\end{tabular}} & & \\
\hline RT 3 & & & & & \\
\hline RT 4 & & & \multirow{11}{*}{ medium } & & 1 \\
\hline RT 5 & & & & & 10 \\
\hline RT 6 & & 15 & & & \multirow{5}{*}{0} \\
\hline RT 7 & 1 & \multirow{8}{*}{0} & & & \\
\hline RT 8 & 75 & & & & \\
\hline RT 9 & 340 & & & & \\
\hline RT 10 & \multirow{2}{*}{15} & & & \multirow{5}{*}{ diffuse } & \\
\hline RT 11 & & & & & 1 \\
\hline RT12 & \multirow{3}{*}{75} & & & & 0 \\
\hline RT 13 & & & & & 1 \\
\hline RT 14 & & & & & 0,5 \\
\hline
\end{tabular}

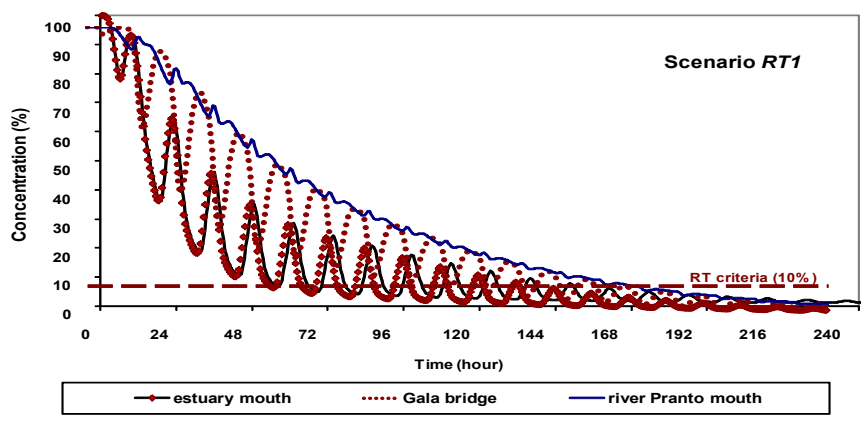

Figure 9: Transport module results for scenario RT1 (Gala station). 
The permanence of a constituent into any elementary volume of the modelled domain can be calculated as the time range witch its concentration remains above the concerning reference conditions (blank or residual concentration).

\section{Results and discussion}

Hydrodynamic results allowed to evaluate the magnitude of currents velocity in both arms during ebbing and flooding situations, and to assess the influence of tidal and freshwater inflows regimes (fig. 10).
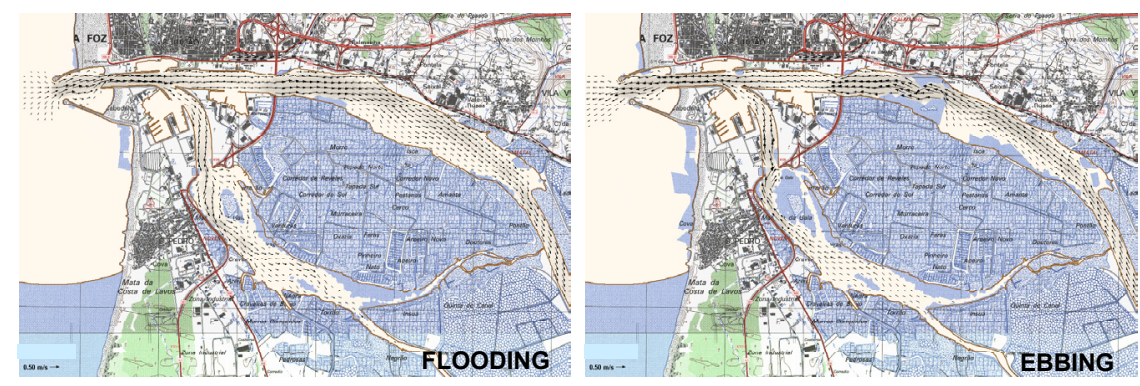

Figure 10: Maximum current velocities in the Mondego estuary (spring tide).

Considering a typical spring tide in this mesotidal estuary, the higher velocity values in the southern arm occur near Gala Bridge, reaching 0.35 to $0.70 \mathrm{~m} . \mathrm{s}^{-1}$, while in the northern arm these values are lower, between 0.33 and $0.60 \mathrm{~m} . \mathrm{s}^{-1}$, at about $1 \mathrm{~km}$ upstream the Figueira da Foz Bridge.

Hydrodynamic modelling has shown the occurrence of a delay between the flooding begin on these two arms of Mondego estuary. Moreover, in the southern arm, the flooding time, witch decreases at the inner zones, is much smaller than ebbing time, due to shallow waters and to large intertidal mudflats areas.

This asymmetry is influenced by tidal regime and has a fast increase into the inner areas of this arm reaching 2.5 hours: 5 hours for flooding and 7.5 hours for ebbing time (fig. 11).

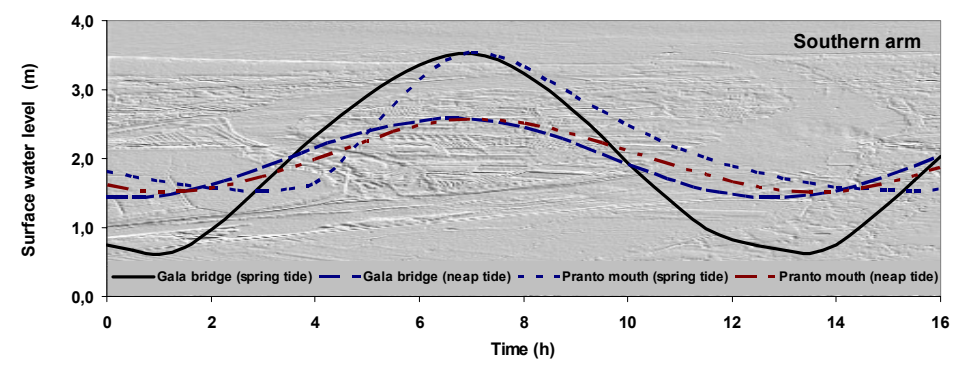

Figure 11: Effect of tidal regime on flooding and ebbing duration asymmetry in the south arm of the Mondego estuary. 
The river Pranto inflow in estuary southern arm has shown a strong influence on salinity distribution decreasing drastically its values to a range far from the most favourable for macroalgae growth, that is about 17-22 psu [18]. Figures 12 illustrate the opening sluices effect on southern arm salinity gradients caused by river Pranto flow discharge of $30 \mathrm{~m}^{3} . \mathrm{s}^{-1}$, during the ending of ebbing and the beginning of flooding periods.
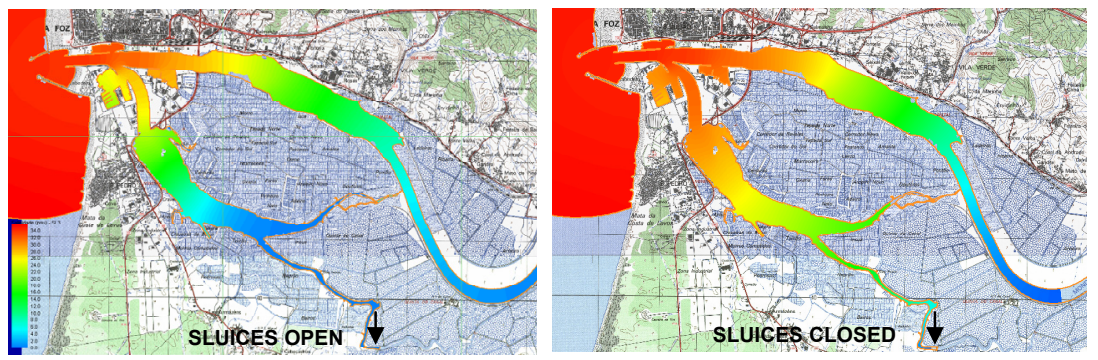

Figure 12: Effect of river Pranto flow discharge on Mondego estuary salinity distribution (high tide).

The same effect was analysed for RT values spatial distribution applying TempResid computing availability. The RT values near Pranto mouth station (S3) can quintuplicate when Alvo sluices are closed (fig. 13).

When Alvo sluices are closed salinity and RT values distributions are strongly related with eutrophication gradients observed in this system over the last twenty years, validating the applied methodology for estuarine water quality assessment.
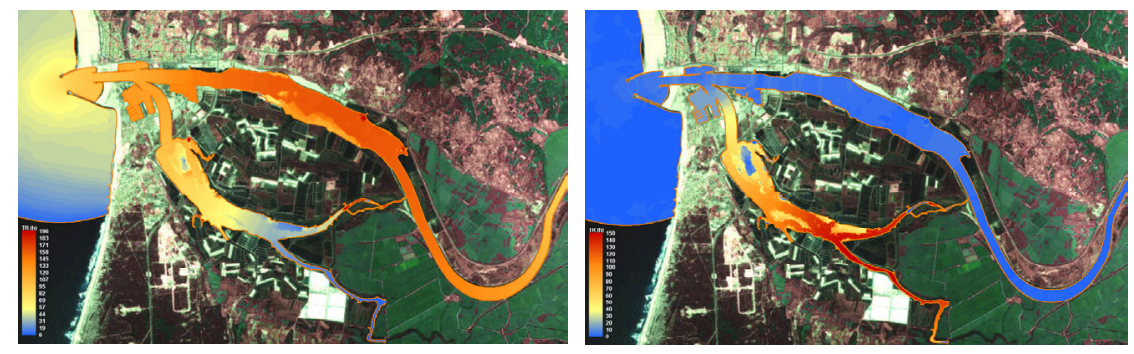

Figure 13: Effect of river Pranto flow discharge on RT distribution (dryweather conditions).

Moreover, MONDEST model can also simulate the effect of nutrients discharge characteristics on estuarine RT values distribution in order to identify the most vulnerable eutrophication areas and to assess the impact of some proposed mitigation and restoration measures: the re-establishment of the south arm riverhead connection; nutrient loading reduction (essentially ammonia). 


\section{Conclusions}

Results obtained from hydrodynamic modelling have shown a strongly asymmetry of ebbing and flooding times at inner estuary south arm areas due to its complex morphology and bathymetry. This information allows a more accurate tidal flow calculation which is the major driving force of the southern arm flushing capacity, when Alvo sluices rest closed. Add to that, River Pranto inflow absence (a typical summer condition) increases drastically RT values in the inner estuary southern arm and, consequently, the nutrients availability for algae uptake is higher, enhancing estuarine eutrophication vulnerability.

Water quality modelling results confirm the eutrophication gradient measured in the Mondego estuary southern arm, validating the methodology applied. For non-conservative substances, like nutrients, residence time highest values are obtained, precisely, at the most eutrophied area observed in this estuarine system.

The MONDEST model developed and applied in this research work allows evaluating and ranking mitigation measures proposals, like nutrient discharges reduction levels, dredging works for hydrodynamic circulation improvement and sluices opening regulation. So, the proposal integrated methodology constitutes a powerful hydroinformatic tool for enhancing estuarine eutrophication vulnerability assessment and providing judicious information for decision support in order to select the most appropriate water quality management practices and to contribute for a truly sustainable ecosystems management.

\section{References}

[1] Paerl, H.W., Assessing and managing nutrient-enhanced eutrophication in estuarine and coastal waters: interactive effects of human and climatic perturbations. Ecological Engineering, 26, pp. 40-54, 2006.

[2] Valiela, I., McClelland, J., Hauxwell, J., Behr, P.J., Hersh, D. \& Foreman, $\mathrm{K}$., Macroalgae blooms in shallow estuaries: controls, ecophysiological and ecosystem consequences. Limnology \& Oceanography, 42, pp. 1105$1118,1997$.

[3] Raffaelli, D., Emmerson, M., Solan, M., Biles, C. \& Paterson, D., Biodiversity and ecosystem processes in shallow coastal waters: an experimental approach. Journal of Sea Research, 49, pp. 133-141, 2003.

[4] Duarte, A.A.L.S., Hydrodynamics influence on estuarine eutrophication processes. PhD Thesis, Dept. of Civil Engineering, University of Minho, Braga, Portugal, 2005. (in Portuguese)

[5] Vieira, J.M.P., Pinho, J.L.S. \& Duarte, A.A.L.S., Eutrophication Vulnerability Analysis: A Case Study. Water Science \& Technology, 37(3), pp. 121-128, 1998.

[6] Jay, D.A., Uncle, R.J., Largier, J., Geyer, W.R., Vallino, J. \& Boynton, W.R., A review of recent development in estuarine scalar flux estimation. Estuaries, 20, pp. 262-280, 1997. 
[7] Dettmann, E., Effect of water residence time on annual export and denitrification of nutrient in estuaries: a model analysis. Estuaries, 24(4), pp. 481-490, 2001.

[8] Oliveira, A. P. \& Baptista, A.M., Diagnostic modeling of residence times in estuaries. Water Resources Research, 33, pp.1935-1946, 1997.

[9] Hattink, J., Wolterbeek, H.T., De Goeij \& Jeroen, J.M., Influence of salinity and eutrophication on bioaccumulation of ${ }^{99}$ technetium in duckweed. Environmental Toxicology and Chemistry, 20, pp. 996-1002, 2001.

[10] Duarte, A.A.L.S., Pinho, J.L.S., Vieira, J.M.P. \& Seabra-Santos, F., Hydrodynamic modelling for Mondego estuary water quality management (Chapter 1.3). Aquatic ecology of the Mondego river basin. Global importance of local experience, eds. Pardal M.A., Marques J.C. \& Graça M.A.S., Coimbra University Press, Coimbra, Portugal, pp. 29-42, 2002.

[11] Pardal, M.A., Cardoso, P.G., Sousa, J.P., Marques, J.C. \& Raffaelli, D., Assessing environmental quality: a novel approach. Marine Ecology Progress Series, 267, pp. 1-8, 2004.

[12] Dolbeth, M., Cardoso, P.G., Ferreira, S.M., Verdelhos, T., Raffaelli, D. \& Pardal, M.A., Anthropogenic and natural disturbance effects on a macrobenthic estuarine community over a 10-year period. Marine Pollution Bulletin, 54, pp. 576-585, 2007.

[13] Duarte, A.A.L.S., Pinho, J.L.S., Pardal, M.A., Neto, J.M., Vieira, J.M.P. \& Seabra-Santos, F., Effect of Residence Times on River Mondego Estuary Eutrophication Vulnerability. Water Science and Technology, 44 (2/3), pp. 329-336, 2001.

[14] Duarte, A.A.L.S., Pinho, J.L.S., Vieira, J.M.P., Pardal, M.A. \& Neto, J.M., Hydrodynamics Influence Assessment on Mondego Estuary Eutrophication Process. Proc. of the $2^{\text {nd }}$ World Water Congress, International Water, ed. IWA Publishing, Melbourne, Australia, 2002.

[15] Duarte A.A.L.S. \& Boaventura R.A.R., Pollutant Dispersion Modelling for Portuguese River Water Uses Protection linked to Tracer Dye Experimental Data. Environment and Development, 4(12), pp. 1047-1056, 2008.

[16] WES-HL, Users Guide to RMA2 Version 4.3. US Army Corps of Engineers, Waterways Experiment Station Hydraulics Laboratory, Vicksburg, USA, 1996.

[17] BOSS SMS, Boss Surface Modeling System - User's Manual, Brigham Young University, USA, 1996.

[18] Martins, I., Paradal, M.A., Lillebo, A.I., Lindt, M.R., Marques, J.C., Hydrodynamics as a major factor controlling the ocurrence of green macroalgal blooms in a eutrophic estuary: a case study on the influence of precipitation and river management. Estuarine Coastal and Shelf Science, 52, pp. 165-177, 2001. 